\title{
Pain Management: Is it the Time to Reconsider Using Opioids?
}

\section{Viroj Wiwanitkit ${ }^{\star}$}

Faculty of Medicine, Hainan Medical University, Thailand

\section{Editorial}

Pain is an unwanted sensation for anyone. The management of pain becomes an important issue in medicine. The pain management is usually important consideration in medical procedure practice and surgery. Several drugs and techniques have been introduced for using in anesthesiology and pain medicine. Opium is a classical plant that human beings knew for years. Modification of opium to produce the pain management product has been done for many decades [1]. However, the big issue is the fact that opium and its derivation, opioids, is considered narcotic and become illegal things if used in nonmedical purpose. It is no doubt that opioids can be effective pain killer for the patient but the important issue is on its side effects. It is the present question whether it is appropriate that opioids are widely used in medical society. Setting a guideline to control the use of opioids becomes important issue in present pain medicine [2,3]. Del Portal et al. noted that "an opioid prescribing guideline significantly decreased the rates at which opioids were prescribed for minor and chronic complaints in an acute care setting [2]." According to the recent guideline by American Society of Interventional Pain Physicians, "opioid therapy may be initiated with low doses and short-acting drugs with appropriate monitoring to provide effective relief and avoid side effects [4]." Nevertheless, as noted by Katz et al. "prescription opioid abuse and addiction are serious problems with growing societal and medical costs [5]." A more strict control by law has also been used in some countries [6,7]. This can be useful for control of some non-ethic practitioner who illegal prescribe or sell opioids [7]. For example, the
Washington State Legislature has just established "new legal standards of practice regarding chronic non-cancer pain management" for control using of opioids [6]. A challenge is whether we can stop using opioids and use other new non-opioids pain killer that are effective to manage the case.

\section{References}

1. Jamison RN, Mao J (2015) Opioid Analgesics. Mayo Clin Proc 90: 957-968.

2. Del Portal DA, Healy ME, Satz WA, McNamara RM (2015) Impact of an Opioid Prescribing Guideline in the Acute Care Setting. J Emerg Med.

3. Fox TR, Li J, Stevens S, Tippie T (2013) A performance improvement prescribing guideline reduces opioid prescriptions for emergency department dental pain patients. Ann Emerg Med 62: 237-240.

4. Manchikanti L, Abdi S, Atluri S, Balog CC, Benyamin RM, et al. (2012) American Society of Interventional Pain Physicians (ASIPP) guidelines for responsible opioid prescribing in chronic non-cancer pain: Part 2--guidance. Pain Physician 15: S67-116.

5. Katz NP, Birnbaum H, Brennan MJ, Freedman JD, Gilmore GP, et al. (2013) Prescription opioid abuse: challenges and opportunities for payers. Am J Manag Care 19: 295-302.

6. Skaer TL, Nwude AC (2015) Opioid Prescribing Laws and Emergency Department Guidelines for Chronic Non-Cancer Pain in Washington State. Pain Pract.

7. Goldenbaum DM, Christopher M, Gallagher RM, Fishman S, Payne R, et al. (2008) Physicians charged with opioid analgesic-prescribing offenses. Pain Med 9: 737-747.
*Corresponding author: Viroj Wiwanitkit, M.D, Professor, Faculty of Medicine Hainan Medical University, Wiwanitkit House, Bangkhae, Bangkok-10160, Thailand, Tel: +66892348832; E-mail: wviroj@yahoo.com

Received September 28, 2015; Accepted September 30, 2015; Published October 05, 2015

Citation: Wiwanitkit V (2015) Pain Management: Is it the Time to Reconsider Using Opioids? Pain Manage Med 1: e101.

Copyright: (c) 2015 Wiwanitkit $\mathrm{V}$. This is an open-access article distributed under the terms of the Creative Commons Attribution License, which permits unrestricted use, distribution, and reproduction in any medium, provided the original author and source are credited. 